\title{
Experimental investigation on machining characteristics of difficult-to-machine materials with Electrochemical Mechanical Polishing
}

\author{
Kohei Otake*, Yuki Ishii* and Wataru Natsu* \\ (Received January 12, 2018) \\ * Tokyo University of Agriculture and Technology, 2-24-16 Nakacho, Koganei, Tokyo 184-8588, Japan
}

\begin{abstract}
:
Difficult-to-machine materials, like titanium alloy, have many advantages such as high hardness and strength. On the other hand, these advantages become obstacle because of the tool wear in the case of mechanical machining, such as cutting and grinding. ECM is effective method for hard materials. However, such as titanium, passivity occurs and machining stops immediately. Electrochemical mechanical polishing (ECMP) is effective for materials that easily become passivated. In this paper, the machining characteristics of difficult-to-machine materials with ECMP are investigated.
\end{abstract}

Keywords: ECM, Electrochemical Mechanical Polishing, Difficult-to-machine materials, Surface roughness

\section{INTRODUCTION}

In recent decades, demand for metal materials which have high strength and corrosion resistance, like titanium and nickel-based alloys, increases in the fields of airplane and atomic furnace[1-2]. However, such materials are known as difficult-to-cut materials because of intensive tool wear. As one of the machining methods for difficult-to-cut materials, electrochemical machining (ECM) is effective. However, in case of some materials, such as titanium, passivity occurs during ECM process and the anodic dissolution stops even if the power supply is applied. Therefore, electrochemical mechanical polishing (ECMP), which combines ECM and mechanical polishing with abrasive grains, is expected to adapt for machining of difficult-to-machine materials [3], since the passive film can be removed with mechanical polishing.

Kimoto et al. [4] researched about electrochemical mechanical buffing (ECMB) for stainless. They reported that the surface roughness could be reduced to $R \max 0.05 \mu \mathrm{m}$ by ECMB. Kamata et al. [5] reported about electrochemical mechanical polishing for titanium. The surface roughness can be reduced until a mirror finish $(\mathrm{Rz} 0.05 \mu \mathrm{m})$ is obtained.

In this paper, we will report experimentally obtained machining characteristics for difficult-to-machine materials such as titanium, titanium alloy, Inconel600, niobium, tungsten and tungsten carbide with ECMP. From the result of experiment, we evaluate materials which are suitable to be machined with ECMP. Moreover, in order to adopt ECMP for shape generation, we did experiments with a small polisher to generate the shape, and will report the possibility of complex shape machining with ECMP.

\section{PRINCIPLE AND EXPERIMENTAL EQUIPMENT OF ECMP}

\subsection{Principle of ECMP}

Fig. 1 shows the machining principle of ECMP. As a voltage applied to workpiece, electrolytic reactions occur and the anode material dissolves into the electrolyte as ions. At the same time, passive film forms by oxidation and prevent the flow of electric current, especially when titanium, tungsten and their alloys are machining. Therefore, it is necessary to remove the passive film during ECM process for continuous anodic dissolution. In the case of ECMP for materials that a severe passive film is likely to be generated, the sharp protruding portions covered by the passive film will be removed by abrasive grain, thus workpiece is planarized gradually. ECMP has following advantages. (1) It does not need to use toxic electrolytes to remove the oxide film. (2) The load in ECMP is quite lower, thus generation of affected layer can be avoided.

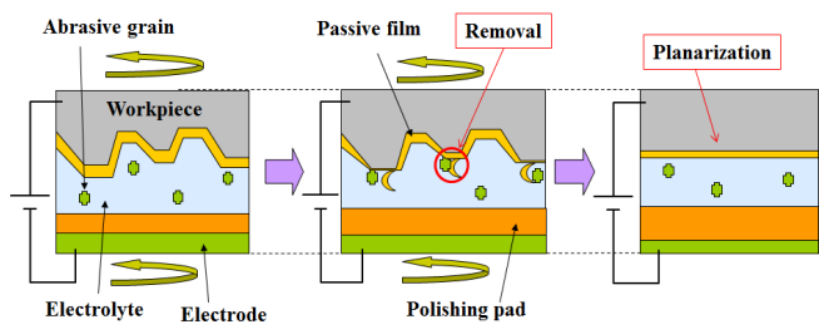

Fig.1 Machining principle of ECMP 


\subsection{Experimental Equipment}

Fig.2 shows experimental equipment used in this research. Metallic workpieces with a dimension of 5 $\mathrm{mm} \times 12 \mathrm{~mm}$ were attached to the workpiece rotating head, and the polishing pad made by non-woven and plastics was pasted to platen. The polishing pad has two functions; acting as a polishing tool and keeping electrolyte. Platen was set to cathode. Electrolyte which contains abrasive grains was supplied by an external feed unit. Workpieces were mounted on the bottom surface of the fixing jig and pressed to the polishing pad by a controlled air pressure. Before ECMP, all samples were lapped with slurry which contained diamond grains of an average particle size of $3 \mu \mathrm{m}$.

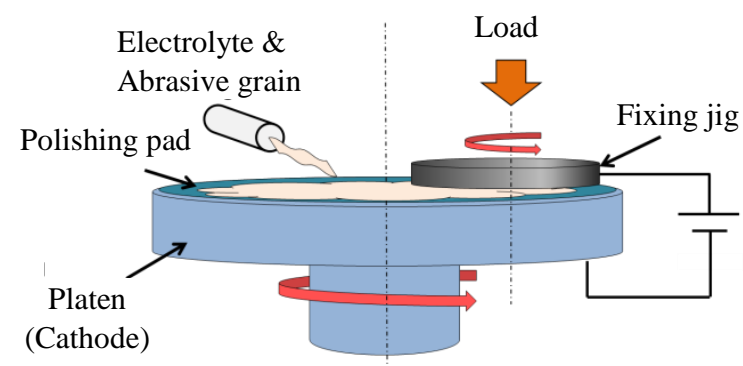

Fig.2 Schematic experimental equipment

\section{RELATIONSHIP BETWEEN VOLTAGE AND MACHINING CHARACTERISTICS}

Machining characteristics with ECMP are determined by applied voltage, concentration of electrolyte, rotations of platen. In particular, the applied voltage exercises a potent influence on the finishing of machined surface. Therefore, optimum voltage for each material should be determined in advance. In this chapter, we investigated relationships between applied voltage and surface roughness for different materials as titanium (grade2), titanium alloy (Ti-6Al-4V), Inconcel600, niobium, tungsten and tungsten carbide. From the result, we selected the most suitable voltage for reducing the surface roughness. Experimental conditions are shown in table 1.

Relationships between applied voltage and surface roughness of each material are shown in Fig.3. As shown in the figure, surface roughness changes with applied voltage. Now, we focus on the result of titanium for instance. Surface roughness is not affected by increasing of applied voltage until $20 \mathrm{~V}$. However, surface roughness deteriorates drastically when the applied voltage exceeds $20 \mathrm{~V}$. This trend can be seen for all materials. Surface roughness of tungsten and tungsten carbide becomes worse than that before ECMP. The roughness of tungsten before
ECMP is Ra $0.014 \mu \mathrm{m}$, while that of tungsten carbide is $\mathrm{Ra} 0.018 \mu \mathrm{m}$. This finding indicates that ECMP is not suitable for machining of tungsten and tungsten carbide under the conditions used in this research. Voltages at which the smoothest surface roughness is obtained in this chapter were used in following chapter.

Results of machining amount of each material, titanium, titanium alloy, niobium and inconel600 under different voltage are shown in Fig.4. Machining amount was obtained from the mass difference before and after ECMP. As shown in Fig.4,

Table 1 Experimental condition of polishing

\begin{tabular}{c|c}
\hline Electrolyte & $20 \mathrm{wt} \% \mathrm{NaNO}_{3} \mathrm{aq}$ \\
\hline Abrasive grain & $8 \mathrm{wt} \%$ Colloidal silica \\
\hline Machining time & $10 \mathrm{~min}$ \\
\hline Rotation speed & Head $20 \mathrm{rpm}$, Platen $50 \mathrm{rpm}$ \\
\hline Polishing pressure & $0.36 \mathrm{MPa}$ \\
\hline
\end{tabular}

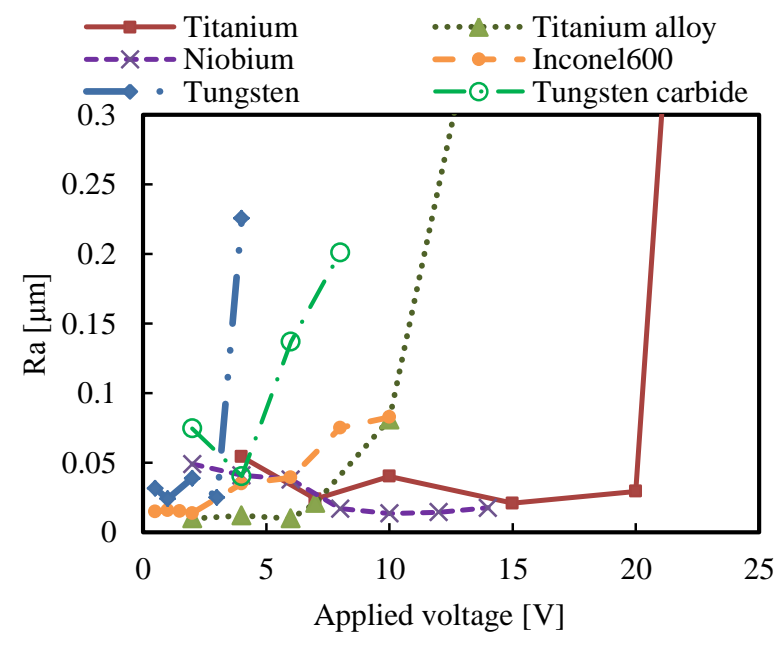

Fig.3 Relationship between Ra and applied voltage

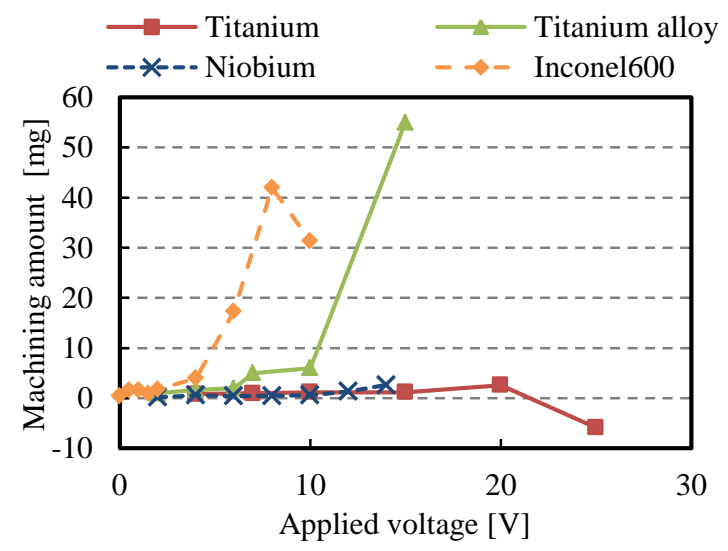

Fig.4 Relationship between machining amount and applied voltage 
machining amount increases with voltage increase in all cases. Under the condition of voltage $24 \mathrm{~V}$, the machining amount of titanium shows a negative value. It means that the workpiece weight increases after ECMP. This occurs as a result of adherence of oxidation products on the surface due to electrolytic reactions.

\section{COMPARISON OF CHARACTERISTICS WITH ECMP, EMP AND MP}

The optimum voltage for surface roughness was obtained in chapter 3 . In this chapter, materials were machined in three ways, ECMP, electrochemical polishing (ECP) and mechanical polishing (MP). Here, ECP is an electrochemical polishing process without mechanical polishing, while MP is a mechanical polishing process without applying voltage between the tool and the workpiece. To evaluate effectiveness of these three methods, machining amount and surface roughness Ra were measured. Machining time is 30 minutes. The other conditions are as the same in table 1. As examples, results of titanium, titanium alloy, Inconel600 and niobium are shown in Fig.5.

As shown in Fig.5(a), machining amount of titanium by ECMP is larger than the sum of ECP and MP. Therefore, we can say that ECMP has a synergistic effect, that means the effect arising between ECP and MP produces an effect greater than the sum of their individual effects. In addition, the surface roughness improves too. As shown in Fig.5(b), although the machining amount of ECMP is larger than that by other methods, there is not synergistic effect which shows in the titanium experiment. As shown in Fig.5(c), although the machining amount of Inconel 600 by ECMP is larger than the sum of ECP and MP, there is no marked difference in the surface roughness. Finally, as shown in Fig.5(d), the surface roughness of ECMP is superior to any other method in the case of niobium, although the machining amount by ECMP is not larger than sum of ECP and MP.

Table 2 shows effectiveness in terms of machining amount and surface roughness with ECMP for each material. In the item of machining amount, a double circle means that machining amount of ECMP is larger than the sum of ECP and MP. A single circle means that, although the machining amount of ECMP is not larger than the sum of EMP and MP, ECMP has the largest machining amount in three methods. A cross mark means the cases other than the above two cases. In the item of surface roughness, a double circle means that the surface with ECMP has the smallest value of surface roughness in three methods. A single circle means that no significant difference was found in three methods. A cross mark means the cases other than these two cases.

As shown in Table 2, ECMP for titanium and niobium are effective in terms of surface roughness. There are similarities in ECMP for these two materials, that is, the surface roughness of these materials did not become worse even in comparatively high voltage region as shown in Fig.3.

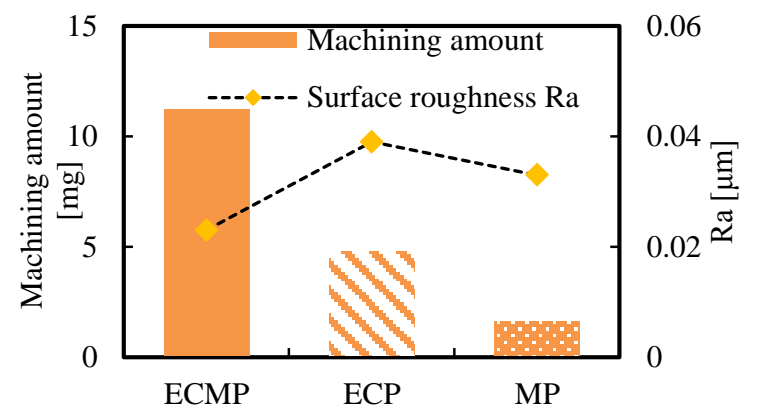

a) Titanium

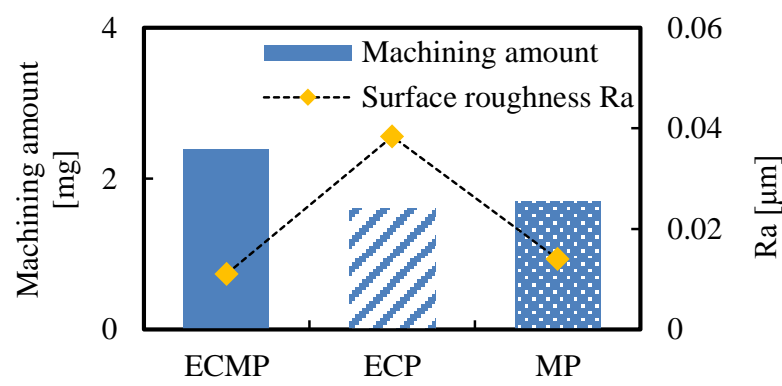

b) Titanium allov

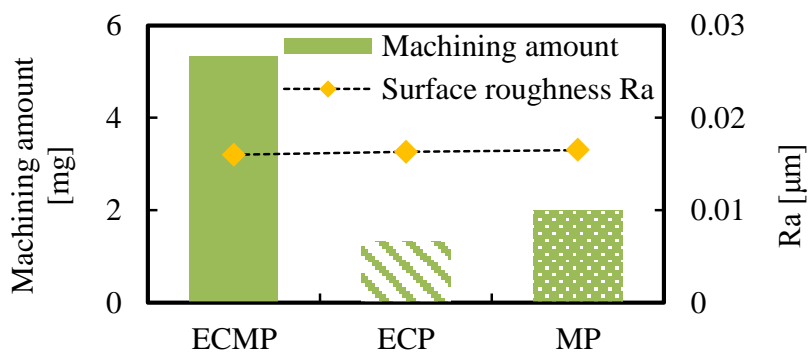

c) Inconel600

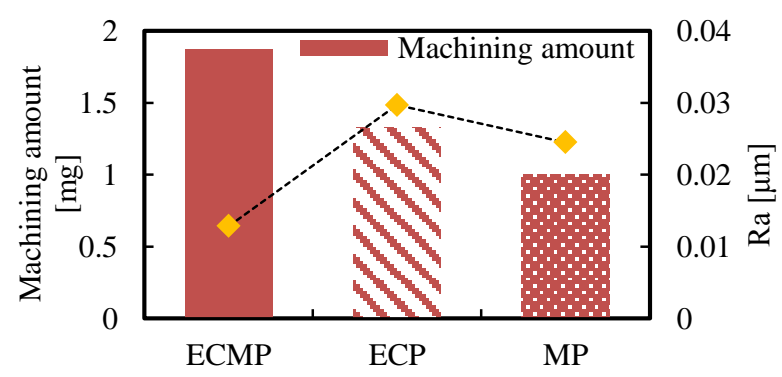

d) Niobium

Fig.5 Machining amount and surface roughness 
In terms of machining amount and surface roughness, ECMP is not suitable for tungsten and tungsten carbide, because the surface roughness of those materials get worse even in low voltage region.

Table 2 Effectiveness of ECMP for each materials

\begin{tabular}{c|c|c}
\hline & $\begin{array}{c}\text { Machining } \\
\text { amount }\end{array}$ & $\begin{array}{c}\text { Surface } \\
\text { roughness }\end{array}$ \\
\hline Titanium & $\bigcirc$ & $\bigcirc$ \\
\hline Ti-6Al-4V & $\bigcirc$ & $\bigcirc$ \\
\hline Niobium & $\bigcirc$ & $\bigcirc$ \\
\hline Inconel600 & $\bigcirc$ & $\bigcirc$ \\
\hline Tungsten & $\times$ & $\times$ \\
\hline Tungsten & $\times$ & $\times$ \\
carbide & & \\
\hline
\end{tabular}

\section{INVESTIGATIONS OF HARDNESS CHANGE WITH ECMP}

Since the growth of oxide film and removal of micro-cracking on the workpiece surface, material properties may change with ECMP process. Hence, we executed the anticorrosion test by sulfuric acid aqueous solution, Charpy impact test and Vickers hardness test for the titanium and titanium alloy samples. About the anticorrosion test and Charpy impact test, no marked differences were found in the trend. Results of Vickers hardness test are discussed here.

Titanium specimens were polished with ECMP, under the conditions of voltage changed between $0 \mathrm{~V}$ to $24 \mathrm{~V}$ by $4 \mathrm{~V}$ each. Titanium alloy specimens were polished with ECMP, under the conditions of voltage changed between $0 \mathrm{~V}$ to $6 \mathrm{~V}$ by $2 \mathrm{~V}$ each. The polishing process was carried out 10 minutes. Conditions of Vickers hardness test is shown in table 3. According to the ASTM standards, Vickers hardness of titanium (grade 2) and titanium alloy (Ti-6Al-4V) are HV 145 and HV 349, respectively.

Fig. 6 shows the test result about titanium. When the voltage is smaller than $20 \mathrm{~V}$, the higher applied voltage is, the more surface hardness increases, although the hardness shows a peak under $10 \mathrm{~V}$. When the voltage is increased to $24 \mathrm{~V}$, hardness decreases sharply. In the case of titanium alloy shown in Fig.7, the more applied voltage increases, the more surface hardness decreases, and it decreases sharply in $6 \mathrm{~V}$. By comparing the change in the surface hardness shown in Fig.6 and Fig.7 with the change in the surface roughness shown in Fig.3, we can find that a rougher surface corresponds to a lower hardness. The reason is considered that the surface becomes rough and the hardness decreases due to formation of oxidation film when the voltage is increased to a certain value, although this consideration is not confirmed yet.

Table 3 Conditions of Vickers hardness test

\begin{tabular}{c|c}
\hline measuring equipment & SHIMADZU HMV-G \\
\hline test force & HV 0.1 $(980.7 \mathrm{mN})$ \\
\hline
\end{tabular}

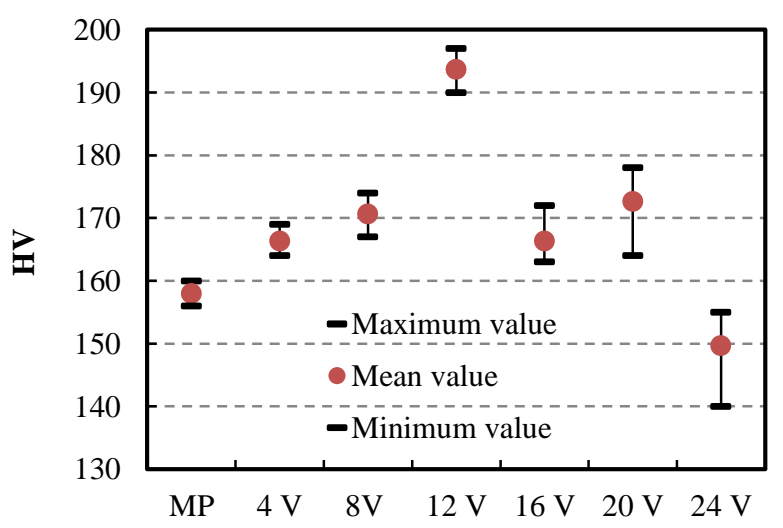

Fig.6 Vickers hardness of Ti (grade 2)

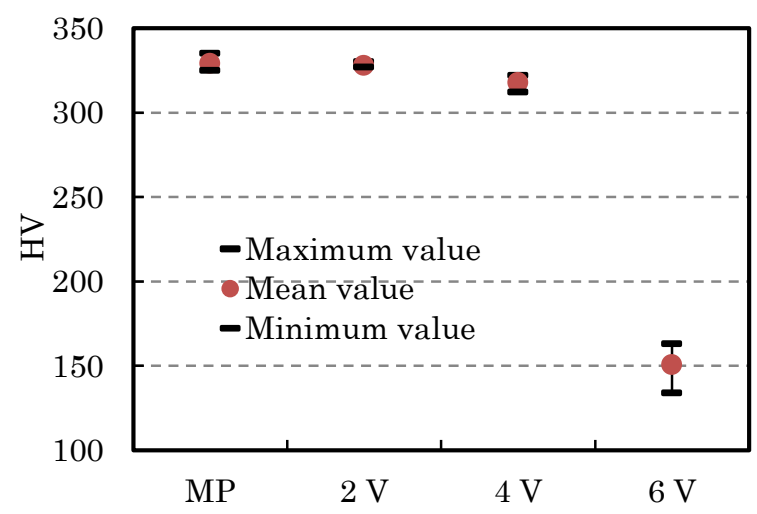

Fig.7 Vickers hardness of Ti-6Al-4V

\section{POSSIBILITY OF ECMP WITH SMALL POLISHER}

In chapter 4, ECMP for titanium was approved to be valid in machining amount and surface roughness. However, the above experiments were restricted to the flat surface machining because polishing was conducted by a polishing pad. Since more and more titanium and titanium alloy are used for artificial bones because of biological compatibility, machining method of complicated shape for these materials is needed. We examined the possibility to generate the 
complicated shape with ECMP by using a small polisher.

In electrochemical machining, removing amount is represented by faraday's law of electrolysis.

$$
m=\eta \frac{A I t}{n F}
$$

Where, $F$ is Faraday constant, $A$ is atomic weight, $I$ is current value, $t$ is energizing time, $n$ is valence and $\eta$ is current efficiency. Meanwhile, machining amount with bonded abrasive grain polishing $\mathrm{g}$ is defined by following equation,

$$
g=k v p t
$$

Where, $k$ is machining constant, $p$ is polishing pressure, $v$ is relative velocity between tool and workpiece and $t$ is dwell time of tool. The dwell time is defined as the time period for the polishing tool to stay at a certain unit area on the workpiece surface in this research. According to equation (1) and (2), machining amount with ECMP $M$ is represented by following equation.

$$
M=f(I \cdot v \cdot p \cdot t)
$$

According to equation (3), we can control machining amount of ECMP by four ways; (1) control by current value. (2) control by dwell time of tool. (3) control by polishing pressure. (4) control by relative velocity between tool and workpiece. Meanwhile, the current is determined by the applied voltage, and the dwell time is determined by the tool scanning speed. In this paper, we experimented with varying voltage value and scanning speed.

\subsection{Influence of Applied Voltage}

In this section, we experimented under various voltages $0 \mathrm{~V}, 10 \mathrm{~V}, 15 \mathrm{~V}$ and $20 \mathrm{~V}$ to survey the effects of voltage value.

Table 4 Experimental conditions

\begin{tabular}{c|c}
\hline Workpiece & $99.5 \% \mathrm{Ti}$ \\
\hline Electrolyte & $20 \mathrm{wt} \% \mathrm{NaNO}_{3}$ solution \\
\hline Polishing tool & $\begin{array}{c}\phi 6 \mathrm{~mm}, V_{\text {Vitrified bonded }} \\
\mathrm{Al}_{2} \mathrm{O}_{3}(\# 100)\end{array}$ \\
\hline Rotation speed & $600 \mathrm{rpm}$ \\
\hline Scanning speed & $0.5 \mathrm{~mm} / \mathrm{min}$ \\
\hline Applied voltage & $0 \sim 20 \mathrm{~V}$ \\
\hline Load & $100 \mathrm{~g}$ \\
\hline
\end{tabular}

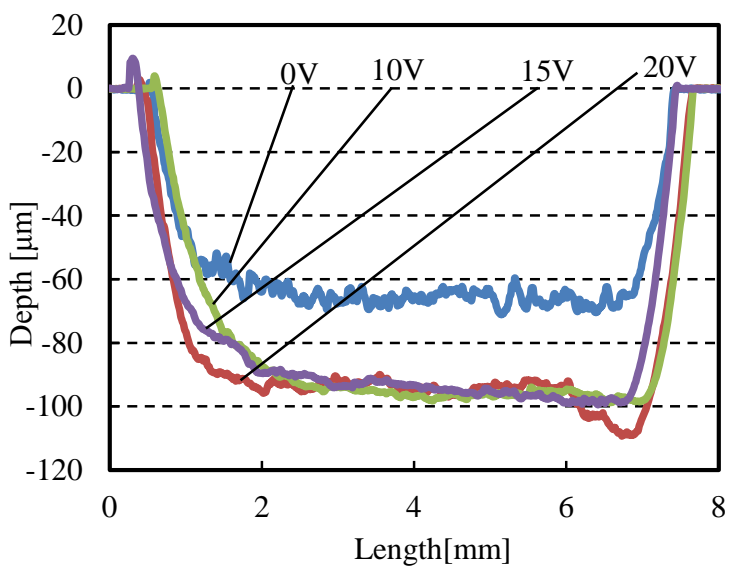

Fig. 8 Measurement result of polished surface

The diameter of small polisher is $6 \mathrm{~mm}$. Table 4 shows experimental conditions and Fig.8 shows measured results of groove shape. The groove was produced by scanning the polishing $6 \mathrm{~mm}$ in a straight path. Groove shape was measured with a shape measuring instrument in the middle of the groove and in the scanning direction (manufactured by Mitutoyo Co.,Ltd, CV-3100S4).

As a result of Fig.8, the machining amount above $10 \mathrm{~V}$ is larger than that of $0 \mathrm{~V}$ and the machining amount is nearly the same under the conditions between 10 and $20 \mathrm{~V}$. From the above experimental results, it is known that controlling machining amount by applied voltage is difficult with ECMP using the small polisher.

\subsection{Influences of Scanning Speed}

In this chapter, experimental results of influence of tool scanning speed on machining characteristics will be explained, when polishing a simple groove with $6 \mathrm{~mm}$ length under different scanning speed. Fig.9 shows relationship between depth and scanning

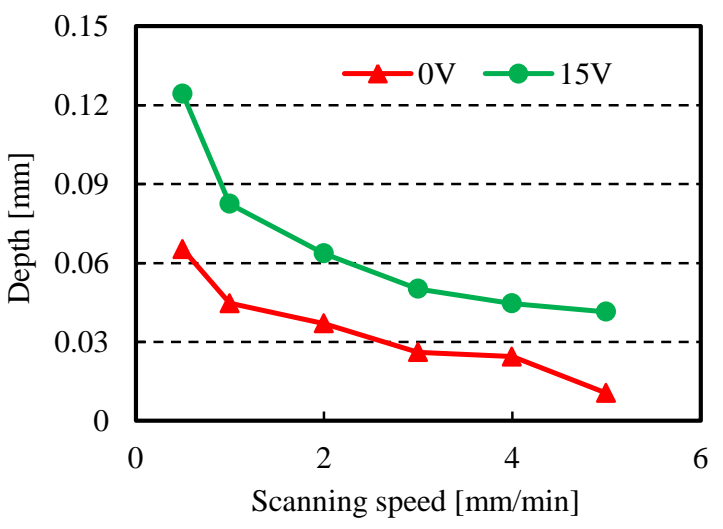

Fig.9 Relationship of processing depth and scanning speed 
speed. It is found that depth of machined groove decrease with increasing scanning speed. This decrease in depth is caused by decrease in dwell due to increase in tool scanning speed. Also, the groove depth in condition of $15 \mathrm{~V}$ is larger than that of $0 \mathrm{~V}$. From the above result, machining amount can be effectively controlled by scanning speed.

\subsection{Shape Generation with Controlled Scanning Speed}

In order to obtain a groove with different depth and verify the effectiveness of depth control by scanning speed, machining was carried out by changing the scanning speed during one scan at a pitch of $30 \mu \mathrm{m}$, while keeping the applied voltage constant at $15 \mathrm{~V}$. Fig. 10 shows measurement result of polished surface and scanning speed. It can be seen that, the slower the scanning speed is, the deeper the groove is polished. This result shows that complicated shapes could be created by controlled scanning speed.

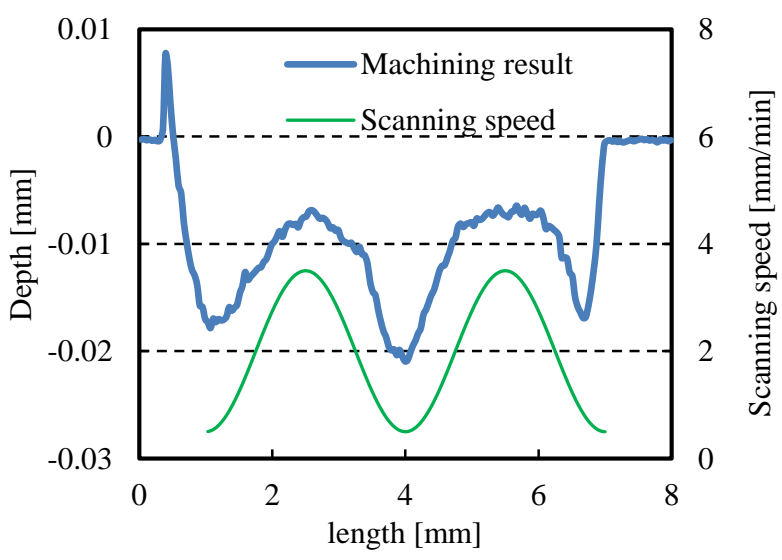

Fig.10 Measurement result of polished surface and scanning speed

\section{CONCLUSIONS}

In this research, ECMP characteristics of difficult-to-machine materials were investigated experimentally. In addition, possibility of shape generation by ECMP with a small polishing tool was investigated. The results are summarized as follows:

(1) There exists optimal machining voltage to improve surface roughness for each material.

(2) ECMP is valid for titanium, niobium and Inconel 600 for improving surface roughness and machining amount, respectively.

(3) Generation of complex shape with ECMP is possible by scanning speed control.

\section{ACKNOWLEDGEMENTS}

This research was supported by the Cross-ministerial Strategic Innovation Promotion Program (SIP) from Japanese government.

\section{REFERENCES}

[1] The Japanese titanium society (2007), Metallic Material to Utilize in the Field, Japanese Industrial Standards Committee, pp.130-135. (in Japanese)

[2] M. kowaka (1983), Corrosion Damage and Protection Technology of Metal, Agune Shofu Sha. (in Japanese)

[3] Y. Kimoto el al. (1998), A Study on High Shape Accuracy Electrolytic-Abrasive Mirror Finishing, Journal of the Japan Society of Precision Engineering Vol.54, No.2, pp.353-358. (in Japanese)

[4] Y. Kimoto el al. (1978), Electrolytic Mirror Polishing Assisted by Mechanical Abrasions of Stainless Steel, Journal of the Japan Society of Electrical Machining Engineers, Vol.12, No.23, pp.1-11. (in Japanese)

[5] H. Kamada et al. (1989), A Study of Mirror Finishing of Titanium by Electrolytic-Abrasive Combined Method, Proceedings of ISEM-9, pp.111-114. 